\title{
Synthesis of an Inhibitor of Histone Lysine Demethylases KDM2/7
}

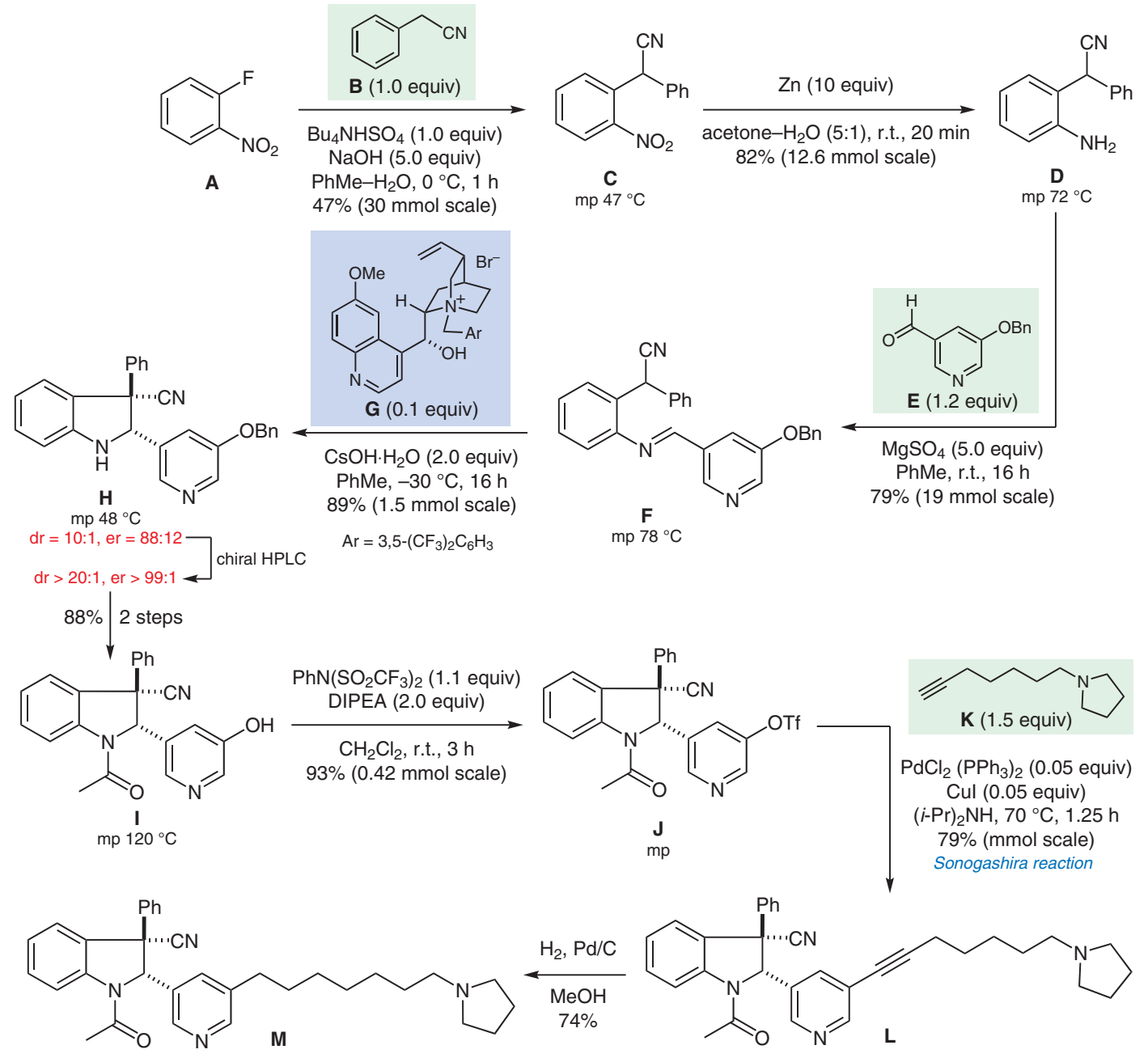

Synthesis of Natural

Products and

Potential Drugs

histone lysine demethylases KDM2/7 inhibitor

$6 \pi$ electrocyclization indolines

organocatalysis

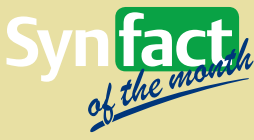

Significance: The target molecule $\mathbf{M}$ is a first-inclass highly selective cell-active inhibitor of the histone lysine demethylases KDM2/7 that are involved in epigenetic gene expression. In total 45 racemic $\mathrm{N}$-acyl indoline derivatives were prepared, from which the enantiomers of $\mathbf{M}$ were selected for further evaluation.

SYNFACTS Contributors: Philip Kocienski

Synfacts 2018, 14(02), 0113 Published online: 18.01.2018 Dol: 10.1055/s-0037-1609195; Reg-No.: K06118SF
Comment: Synthesis of the indoline $(S, S)-H$ entails treatment of the $\mathrm{N}$-aryl imine $\mathbf{F}$ with cesium hydroxide under phase-transfer conditions in the presence of the quinine-derived salt $\mathbf{G}$ ( 0.1 equiv). A delocalized 2-aza-pentadienyl anion is generated that undergoes $6 \pi$ electrocyclization in $89 \%$ yield $(d r=10: 1$, er $=88: 12)$. Preparative chiral HPLC then delivered $\mathbf{H}$ with $\mathrm{dr}>20: 1$ and er $>99: 1$. For details on the asymmetric electrocyclization, see: E. E. Maciver, S. Thompson, M. D. Smith Angew. Chem. Int. Ed. 2009, 48, 9979). 